\title{
İstanbul'da, Restoranlarda Döner Kebaplarla Servis Edilen Taze Garnitürlerin Mikrobiyolojik Güvenliğinin Belirlenmesi Üzerine Çalışmalar
}

\section{Assessments on Determining the Microbiological Safety of Fresh Garnishes Served with Doner Kebab in Istanbul Restaurants}

\author{
Ayla Ünver Alçay ${ }^{\oplus}$ \\ İstanbul Aydın Üniversitesi, Anadolu BíL Meslek Yüksekokulu, Gıda İşleme Bölümü, Gıda Teknolojisi Programı, İstanbul, Türkiye
}

Atıf/Cite as: Ünver Alçay A. İstanbul'da, restoranlarda döner kebaplarla servis edilen taze garnitürlerin mikrobiyolojik güvenliğinin belirlenmesi üzerine çalışmalar. Turk Mikrobiyol Cemiy Derg. 2021;51(3):276-87.

ÖZ

Alındığı tarih / Received:

15.03.2021 / 15.March.2021

Kabul tarihi / Accepted:

17.04.2021 / 17.April.2021

Yayın tarihi / Publication date:

07.09.2021/ 07.September.2021

\section{ORCiD Kayd}

A. Ünver Alçay 0000-0003-3254-155X

aylaalcay@aydin.edu.tr
Amaç: Bu çalışmanın amacı, döner kebap restoranlarında servis edilen bazı çiğ sebzelerin (havuç, marul ve maydanoz vb.) mikrobiyolojik güvenliğini belirlemektir. Ayrıca bu ürünlerin dekontaminasyonunda yaygın olarak kullanılan üzüm sirkesinin antibakteriyel aktivitesi de değerlendirilmiștir.

Yöntem: Örnek olarak, ístanbul'da dönerle servis edilen 30 adet garnitür aseptik sartlarda, rastgele seçilmis 30 restorandan alınmış ve toplam mezofilik aerob bakteri sayısı, Enterobacteriaceae spp. sayısı, Escherichia coli, Salmonella spp. ve Staphylococcus aureus mikrobiyal kalite göstergesi olarak araştırılmıştır. İkinci aşamada, üç farklı sirke örneğinin, garnitürlerden izole edilen bazı Gram negatif bakteriler ve Staphylococcus aureus suşları üzerine antimikrobiyal etkisi minimum inhibe edici konsantrasyon ile incelenmistir.

Bulgular: Toplam aerobik mezofilik bakteri $1.5 \times 10^{4}-5.6 \times 10^{7} \mathrm{cfu} / \mathrm{g}$ [4.17-7.24 $\log _{10}$ Enterobacteriaceae spp. $<10-1.2 \times 10^{7} \mathrm{cfu} / \mathrm{g}\left(<1-7.07 \log _{10}\right)$, koagulaz pozitif Staphylococcus $<10-3.4 \times 10^{2} \mathrm{cfu} / \mathrm{g}\left(<1-2.53 \log _{10}\right)$, Escherichia coli sayısı ise $\left.<10-2 \times 10^{1} \mathrm{cfu} / \mathrm{g}\left(<1-1.30 \log _{10}\right)\right]$ miktarında bulunmuştur. Incelenen örneklerin \%20'sinde toplam aerobik koloni sayısının $\geq 107, \% 60$ 'ında Enterobacteriaceae spp. sayısının $\geq 10^{4}$, koagulaz pozitif Staphylococcus sayısının \%50'sinde $>10^{2} \mathrm{cfu} / \mathrm{g}$ düzeyinde belirlenmesi ve bir örnekte de Salmonella spp. saptanmıs olmas yetersiz mikrobiyolojik kaliteyi ortaya koymuştur. Garnitürlerden Klebsiella pneumoniae, Klebsiella ozaenae, Klebsiella oxytoca, Escherichia coli, Enterebacter aerogenes, Escherichia hermanii, Enterobacter cloacae, Hafnia alvei, Aeromonas hydrophila, Citrobacter freundii, Burkholderia pseudomallei, Serratia odorifera biogp 1 ve Staphylococcus aureus identifive edilmistir. Üzüm sirkelerinin \%1.5-6.25 arasında değișen konsantrasyonlarda incelenen mikroorganizmalara antimikrobiyal etkinliği olduğu saptanmıştır.

Sonuç: Incelenen garnitür örneklerinin gıda güvenliği ve halk sağlığı açısından risk oluşturabileceği sonucuna varılmıştır ve bu sonuçlar restoranlarda ısıl işlem uygulanmamış taze gıdalarda iyi hijyen uygulamalarına duyulan gereksinimi göstermektedir.

Anahtar kelimeler: Döner garnitürleri, mikrobiyolojik kalite, üzüm sirkesinin antibakteriyel etkisi

ABSTRACT

Objective: The aim of this study is to determine the microbiological safety of some raw vegetables (carrot, lettuce, parsley, etc.) served with döner kebab in restaurants. In addition, the antibacterial activity of grape vinegar, which is widely used in restaurants and homes, was evaluated in the decontamination of these products.

Method: Samples of 30 garnishes served with doner kebab in Istanbul were taken from randomly selected 30 restaurants and the total number of mesophilic aerob bacteria (TAMB), Enterobacteriaceae spp. number, Escherichia coli, Salmonella spp. and Staphylococcus aureus were taken as an indicator of microbial quality. Identification study was performed from isolated gram negative bacteria and coagulase positive staphylococci. In the second step, the antimicrobial effects of three different vinegar samples on some gram-negative bacteria and Staphylococcus aureus strains isolated from the garnishes were investigated with the minimum inhibitory concentration.

Results: Total aerobic mesophilic bacteria were found as $1.5 \times 10^{4}-5.6 \times 10^{7} \mathrm{cfu} / \mathrm{g}$ [4.17-7.24 $\log$ (Enterobacteriaceae spp. $<10-1.2 \times 10^{7} \mathrm{cfu} / \mathrm{g}(<1-7.07 \mathrm{log})$ coagulase positive Staphylococcus $<10-3.4 \times 10^{2}$ $c f u / g\left(<1-2.53 \log _{10}\right)$, Esherichia coli $\left.<10-2 \times 10^{1} \mathrm{cfu} / \mathrm{g}\left(<1-1.30 \log _{10}\right)\right]$. The samples were found insufficient for microbiological quality, due to the total number of aerobic colony (TAMB) levels at $10^{7}$ in $20 \%$, Enterobacteriaceae spp. levels at 104 in 60\%, Staphylococcus aureus levels at $\geq 10^{2} \mathrm{cfu} / \mathrm{g}$ in 50\% and Salmonella spp. was found in one sample. Klebsiella pneumoniae, Klebsiella ozaenae, Klebsiella oxytoca, Escherichia coli, Enterebacter aerogenes, Escherichia hermanii, Enterobacter cloacae, Hafnia alvei, Aeromonas hydrophila, Citrobacter freundii, Burkholderia pseudomallei, Serratia odorifera biogp 1 and Staphylococcus aureus were identified from the garnishes. The vinegars were effective on microorganisms at concentrations varying between $1.5 \%$ and $6.25 \%$.

Conclusion: It was concluded that the examined garnish samples may pose a risk forfood safety and public health, and these results show the need for good hygiene practices in fresh foods that are not heat-treated in restaurants.

Keywords: Doner garnishes, microbiological quality, antibacterial effect of grape vinegar

(C) Telif hakkı Türk Mikrobiyoloji Cemiyeti'ne aittir. Logos Tıp Yayıncılık tarafindan yayınlanmaktadır.

Bu dergide yayınlanan bütün makaleler Creative Commons Atf-Gayri Ticari 4.0 Uluslararası Lisansı ile lisanslanmıştır. 


\section{GiRiş}

Gıda kaynaklı hastalıklar nedeniyle dünyada milyonlarca insan her yıl tedavi görmekte ve hatta bazıları ölmektedir. Gıda kaynaklı hastalıklar genellikle hayvansal gıdalardan kaynaklanır, ancak çiğ yenen sebze ve meyveler de önemli bir yere sahiptir. Bitkiler; toprak, su, hava, gübre, insan ve hayvan gibi farklı kaynaklardan gelen mikroorganizmalarla kirlenir. Kullanıma hazır sebzeler genellikle $10^{5}-10^{7} \mathrm{cfu} / \mathrm{g}$ düzeyinde çeşitli mikroorganizma popülasyonları içerir. Bitkilerin doğal florası birbirinden farklı olsa da, genellikle floradaki bakterilerin \% 80 ila \% 90'ını Gram negatif basiller oluşturmaktadır ${ }^{(1)}$. Alcaligenes, Flavobacterium, Achromobacter, Corynebacterium ve Micrococcus, fekal streptokoklar, koliform ve laktik asit bakterilerine ait bakterilere sıklıkla rastlanır. Patojen bakteriler, parazitler ve virüsler gibi mikroorganizmaların varlığı da olasıdır ${ }^{(2)}$. Tarladan çatala kadar çiğ tüketilen sebzeler her aşamada kontamine olabilir. Olası hasat sonrası kaynaklar arasında insanlar, zararlılar (böcekler ve kuşlar dâhil), hasat ve işleme ekipmanları, personel, nakliye ve depolama bulunur. Kullanıma hazır sebzeler, suyla yıkadıktan sonra yerel mikrofloralarının çoğunu korur ve patojenler de içerebilir. Isıl işlem yapılmadan sebze tüketimi ile ilişkili gıda kaynaklı hastalıkları önlemek için etkili ve uygulanabilir sanitasyon yöntemleri gereklidir. Bugün Türkiye'de birçok ev ve işletmede limon suyu ve sirke gibi doğal ürünler yaygın olarak antimikrobiyal olarak kullanılmaktadır ${ }^{(3)}$. Bununla birlikte, kullanım oranları genellikle rastgeledir ve yıkanan sebze üzerine göz kararı eklenir.

Döner kebapları genellikle garnitür olarak adlandırılan domates, marul, havuç ve kırmızı lahana, yeşil biber ve soğan gibi sebzelerle servis edilir. Ingiltere'deki kebap paket servis restoranlarında salata sebze ve soslarının mikrobiyolojik güvenliğini belirlemek için yapılan bir araştırmada, sebze salatası örneğinin yetersiz mikrobiyolojik kalitede olduğu ortaya konmuştur ${ }^{(4)}$. Ülkemizde döner kebabının mikrobiyolojik kalitesi ile ilgili birçok çalışma bulunmakla birlikte, döner kebabı ile servis edilen garnitürler için yapılan bir araştırma yoktur. Garnitürler genellikle büyük miktarlarda hazırlanır ve oda sıcaklığında ve kontaminasyona uygun olarak açık bir şekilde gün boyu servis edilir. Hatta birçok işletmede İstanbul'da garnitürlerin döner ile birlikte sokağa açılmış bir pencere önünde toz, insan ve pestlerle temas durumunda, tezgâh üzerinde bulundurulduğu sıklıkla gözlemlenir.

Bu çalışmanın amacı, İstanbul'da döner ile servis edilen bazı çiğ sebzelerin (domates, havuç, marul, soğan, marul ve maydanoz) mikrobiyal kontaminasyon seviyesini ve mikrobiyal kalitesini belirlemektir. Ayrıca bu ürünlerin dekontaminasyonunda evlerde ve işletmelerde yaygın olarak kullanılan sirke antibakteriyel aktivitesi de değerlendirilmiştir.

\section{GEREÇ ve YÖNTEM}

Örnek alımı: İstanbul merkez ilçelerden, Nisan 2019Temmuz 2020 tarihleri arasında, rastgele örnekleme ile lokanta ve döner servisi yapılan büfelerden toplam 30 ayrı yerden, 30'ar adet garnitür örneği (marul, maydanoz, soğan, havuç ve domatesten oluşan) usulüne uygun olarak, steril kaplara alınmış ve bekletmeden, soğuk şartlarda laboratuvara getirilerek analize başlanmıştır. iki adet ticari üzüm sirkesi, İstanbul'da yerel marketlerden kapalı ambalajlarında ve bir adet geleneksel yöntemle üretilmiş üzüm sirkesi, halk elinden steril bir kaba alınmıştır.

Örneklerin analize hazırlanması: Garnitürler, aseptik şartlarda $25 \mathrm{~g}$ miktarında tartılarak steril bir poşete koyulmuştur. Poşetlere steril $1 / 4$ Ringer (Merck, 115525-Almanya) çözeltisinden $225 \mathrm{ml}$ eklendikten sonra Stomacher (Easy Mix Stomacher, AES Chemunex, Fransa) cihazında homojenize edilmiş ve on katlı dilüsyonlar hazırlanmıştır.

Sirke örneklerinin $\mathrm{pH}$ ve asitlik derecelerinin belirlenmesi: Sirke örnekleri temiz ve kuru bir behere $10 \mathrm{ml}$ miktarında koyularak dijital pH metre (Mettler Toledo, Seven Compact S220, i̇sviçre) ile ölçüm yapılmıştır. Temin edilen sirkelerin asitlik yüzdeleri titrimetrik yöntemle belirlenmiştir ${ }^{(5)}$.

Mikrobiyolojik analizler: Escherichia coli ATCC 25922 (BD Cat. No. 254986), Staphyloccus aureus ATCC 
25923 (BD, Cat. No. 254995) ve Salmonella Typhimurium ATCC (BD Cat. No. 254993) pozitif kontrol suşları olarak kullanılmıştır.

Toplam mezofilik aerobik bakteri sayımı: Her dilüsyondan dökme plak yöntemiyle besiyerlerine Plate Count Agar (PCA) (Merck, 1.05463, Almanya) ekimler yapılmış ve $30 \pm 1^{\circ} \mathrm{C}^{\prime}$ de 3 gün inkübe edilmiştir(6). Koloni görülen petri kapları değerlendirmeye alınarak toplam aerob mezofilik bakteri (TAMB) sayısı hesaplanmıştır.

Enterobacteriaceae spp. sayımı: Tüm dilüsyonlardan, Violet Red Bile Glucose (VRB) Agar (Merck 1.10275, Almanya) besiyerine ekim yapılmış ve $30 \pm 1^{\circ} \mathrm{C}^{\prime}$ de 48 saat inkübe edilmiştir. İnkubasyon sonunda, 1-2 mm çaplı, kırmızı ve etrafında halka şeklinde hale oluşturan kolonilere oksidaz testi (Merck 1.13300, Almanya) uygulanmıştır. Oksidaz negatif sonuç veren tipik koloniler sayılmıştır(7).

Escherichia coli sayımı: ISO 16649-1:2018'e uygun olarak Tryptone Bile X-Glucuronide (TBX) Agar (LAB-M HAL003) besiyeri kullanılmıştır ${ }^{(8)}$. Ekim yapılan besiyerleri $44^{\circ} \mathrm{C}^{\prime}$ de 24 saat süreyle inkübe edilmiş; opak mavimsi yeşil renkteki koloniler sayılarak değerlendirilmiştir.

Koagulaz pozitif stafilokok saptanması ve sayımı: Hazırlanan tüm dilüsyonlardan, Baird Parker Agar (BPA) (Oxoid CM 275) besiyerine $50 \mathrm{ml} / \mathrm{l}$ miktarında Egg Yolk Tellurite Emulsion (Oxoid SR 54) eklenmiş ve oda sıcaklığında besiyeri donması beklendikten sonra her bir seyreltmeden ekim yapılmış ve $37^{\circ} \mathrm{C}^{\prime}$ de 48 saat inkübe edilmiştir. Bu besiyerinde üreyen, şeffaf zonla çevrili, siyah renkli tipik koloniler ile atipik kolonilerden 5'er adet seçilerek koagulaz testi uygulanmıştır. Koagulaz pozitif stafilokok sayısı belirlenmiş ${ }^{(9)}$ ve API ${ }^{\circ}$ Staph Test Kiti (bioMérieux, Fransa) ile identifikasyon yapılmıştır.

Salmonella spp. sayımı: ISO 6579-1 yöntemiyle gerçekleştirilmiştir ${ }^{(10)}$. Örnekler aseptik koşullarda 25 'er g steril Stomacher torbalarına tartılmış ve üzerine steril mezür yardımıyla 225 ml Buffered Peptone Water (BPW, Merck 107228) ilave edilmiştir.
Homojenizasyon işleminden sonra süspansiyon, ön zenginleşme için $37^{\circ} \mathrm{C}^{\prime}$ da 24 saat inkübasyona bırakılmıştır. İnkube edilip, bu örneklerden $0.1 \mathrm{ml}$ alınarak $10 \mathrm{ml}$ Rappaport Vassiliadis Soya (RVS) Broth'a, (LABM, LAB086) bir ml de, $10 \mathrm{ml}$ Muller-Kauffmann Tetrathionate-Novobiocin (MKTTn) Broth'a (LAB202LABM) inoküle edilmiş ve MKTTn Broth'da $37^{\circ} \mathrm{C}^{\prime}$ de 24 saat, RVS Broth'da $41.5^{\circ} \mathrm{C}^{\prime}$ de 24 saat inkübasyona bırakılmıştır. Üreme olan, RVS Broth ve MKTTn Broth besiyerlerinden (Xylose Lysine Desoksikolat (XLD) Agar (LABM-LAB032) ve Salmonella ABC Agar (ABC Agar, LabM, HAL001) selektif besiyerlerine pasaj yapılmış ve $37^{\circ} \mathrm{C} 24$ saat inkübasyona bırakılmıştır. XLD Agar'da siyah, Salmonella ABC Agar besiyerinde ise açık yeşil tonlarında şüpheli kolonilerden saflaştırma için Nutrient Agara (NA, Merck 1.05450) geçilip $37{ }^{\circ} \mathrm{C}$ de 24 saat inkübe edilmiştir. Nutrient agardaki şüpheli kolonilere katalaz ve oksidaz testleri yapılmıştır. Gelişen koloniler öze yardımıyla alınarak oksidaz test stripine (Bactident Oxidase, Merck 113300) sürülmüş ve mor rengin oluşumu oksidaz pozitif olarak değerlendirilmiştir. Katalaz pozitif, oksidaz negatif kolonilerin Api 20 E test stribine (bioMérieux, Fransa) inokulasyonu yapılmıştır. Strip $37^{\circ} \mathrm{C}^{\prime}$ de 24 saat inkübasyona bırakılmıştır. İnternet web tabanından sonuçlar değerlendirilmiştir.

Gram negatif bakterilerin identifikasyonu: İdentifikasyon için API 20E (bioMérieux, Fransa) kiti kullanılmıştır ve yöntem üretici kit talimatına göre uygulanmıştır. Garnitürlerden izole ve identifiye edilen, incelenecek bazı Gram negatif bakteri suşları ve yedi farklı $S$. aureus suşu (Tablo 1 ),$-25^{\circ} \mathrm{C}^{\prime}$ de minimum inhibe edici konsantrasyon tayini yapılana kadar korunmuştur.

Minimum İnhibe Edici Konsantrasyon (MIK) Belirlenmesi: Bütün bakteri suşları çözüldükten sonra, 24 saat $37^{\circ} \mathrm{C}^{\prime}$ de inkübe edilmiş, $\% 0.9$ steril fizyolojik tuzlu su solüsyonuna aktarılmış ve inokulumun yaklaşık $10^{8} \mathrm{cfu} / \mathrm{ml}$ olarak standardize edilmesi için 0.5 McFarland standardına ayarlanmıştır. Minimum inhibitör konsantrasyon (MIC) tayini için mikroplate ile broth dilüsyon metodu kullanılmıştır. Analiz için Muller Hinton Broth (MHB, Merck, 110293) çift kuvvet olarak hazırlanmıştır. Mikroplatelerde, 
Tablo 1. Minimal inhibitör konsantrasyon tayini yapılan suşlar.

\begin{tabular}{ll}
\hline No. & Minimal inhibitör konsantrasyon tayini yapılan suşlar \\
\hline 1 & Enterobacter cloacae \\
2 & Enterobacter aerogenes \\
3 & Enterobacter spp. \\
4 & Klebsiella pneumoniae \\
5 & Escherichia coli \\
6 & Escherichia coli \\
7 & Escherichia hermannii \\
8 & Staphylococcus aureus \\
9 & Staphylococcus aureus \\
10 & Staphylococcus aureus \\
11 & Staphylococcus aureus \\
12 & Staphylococcus aureus \\
13 & Staphylococcus aureus \\
14 & Staphylococcus aureus \\
\hline
\end{tabular}

her kuyucuğa $50 \mu \mathrm{l}$ MHB, $50 \mu \mathrm{l}$ sirke örneği ve $5 \mu \mathrm{l}$ bakteri süspansyonu ilave edilmiştir. Pozitif kontrol olarak sirke çözeltisi yerine steril serum fizyolojik (\%.085 NaCl çözeltisi) koyulmuştur. Her kuyucukta, sirke konsantrasyonu \%0.78, \%1.5, \%3.12, \%6.25, $\% 12.5, \% 25$ ve $\% 50$ olacak şekilde ayarlanmıştır. Daha sonra $37^{\circ} \mathrm{C}^{\prime}$ de 24 saat inkübasyon gerçekleştirilmiştir. Herhangi bir bakteri büyümesini engelleyen en düşük konsantrasyon (üremenin olmadığı kuyucuklar minimal inhibisyon konsantrasyonu) MIK olarak tanımlanmıştır. Bütün testler yeniden üç kere yapılmıştır ${ }^{(11)}$.

İstatistik analiz: Garnitür örneklerine ait mikroorganizma sayıları ortalama logaritmik değerlere çevrilmiş ve SPSS 19 programı ile istatistiki değerlendirmesi yapılmıştır. Sirke örneklerinin, MIK değerleri açısından anlamlı bir farkı olup olmadığının belirlenmesi için Kruskal-Wallis One Way Anova testi kullanılmıştır.

\section{BULGULAR}

İzolasyon ve İdentifikasyon Çalıșmaları ve İstatistik
Değerlendirme Sonuçları: Garnitürlerde ortalama olarak; toplam aerobik mezofilik bakteri $1.5 \times 10^{4}$ $5.6 \times 10^{7} \mathrm{cfu} / \mathrm{g}$ [4.17-7.24 $\log _{10^{\prime}}$; Enterobacteriaceae spp. $<10-1.2 \times 10^{7} \mathrm{cfu} / \mathrm{g}\left(<1-7.07 \log _{10}\right)$, koagulaz pozitif Staphylococcus $<10-3.4 \times 10^{2} \mathrm{cfu} / \mathrm{g} \quad(<1-2.53$ $\left.\log _{10}\right)$, E. coli sayısı ise $<10-2 \times 10^{1} \mathrm{cfu} / \mathrm{g}\left(<1-1.30 \log _{10}\right)$ miktarında bulunmuştur (Tablo 2). Garnitürlerden izole edilen, Gram negatif bakterilerden rastgele seçilen kolonilerden Klebsiella pneumoniae, Klebsiella ozaenae, Klebsiella oxytoca, E. coli, Enterebacter aerogenes, Escherichia hermanii, Enterobacter cloacae, Hafnia alvei, Aeromonas hydrophila, Citrobacter freundii, Burkholderia pseudomallei, Salmonella spp., Serratia odorifera biogp 1 ve ayrıca Baird Parker Agar besiyerinden $S$. aureus identifiye edilmiştir. Garnitür örneklerinin mikrobiyolojik sayım sonuçlarına göre frekans dağılımları Tablo 2 ve betimsel istatistik sonuçları Tablo 3'te görülmektedir.

Mikrobiyolojik analiz sonuçları, Gilbert ve ark.'nın ${ }^{(12)}$ belirttiği "hazır salata sebzeler ve soslar için mikrobiyolojik kriterler"e göre değerlendirilmiştir. Tablo 4 değerlendirme ölçütlerini göstermektedir ${ }^{(12)}$. Incelenen örneklerin altısında toplam aerobik koloni sayısının (TAMB) $\geq 10^{7}$ olduğu belirlendiği için (\%20) tatmin edici olmayan kategoride belirlenmiştir. Incelenen örneklerin 18 tanesi Enterobacteriaceae spp. sayısı $\geq 10^{4}$ şeklinde belirlenmiş olup, tatmin edici değil kategorisindedir. E. coli açısından değerlendirildiğinde, incelenen 30 örnekten 27'si <20 tatmin edici, üç tanesi 20-<100 aralığında yani kabul edilebilir olarak belirlenmiştir. Salmonella spp. ISO 6579-1 yöntemiyle 25 g'de saptanmamıştır. S. aureus $<10-3.4 \times 10^{2} \mathrm{cfu} / \mathrm{g}\left(<1-2.53 \log _{10}\right)$ miktarında belirlenmiştir (Tablo 2).

Tablo 2. Mikrobiyolojik sayım sonuçlarına göre garnitür örneklerinin frekans dağılımları.

\begin{tabular}{|c|c|c|c|c|c|c|c|c|c|c|c|c|c|c|c|c|c|c|}
\hline \multirow[b]{3}{*}{ Ölçütü } & \multirow[b]{3}{*}{$\mathbf{N}$} & \multicolumn{16}{|c|}{ Frekans (f) ve göreli frekans dağılımı (\%) $p_{i}$} & \multirow{3}{*}{$\overline{\mathbf{x}} \pm \mathbf{i n} \overline{\mathbf{x}}$} \\
\hline & & \multicolumn{2}{|c|}{$0-<10$} & \multicolumn{2}{|c|}{$\begin{array}{l}\geq 10- \\
<10^{2}\end{array}$} & \multicolumn{2}{|c|}{$\begin{array}{l}\geq 10^{2}- \\
<10^{3}\end{array}$} & \multicolumn{2}{|c|}{$\begin{array}{l}\geq 10^{3}- \\
<10^{4}\end{array}$} & \multicolumn{2}{|c|}{$\begin{array}{l}\geq 10^{4}- \\
<10^{5}\end{array}$} & \multicolumn{2}{|c|}{$\begin{array}{l}\geq 10^{5}- \\
<10^{6}\end{array}$} & \multicolumn{2}{|c|}{$\begin{array}{l}\geq 10^{6}- \\
<10^{7}\end{array}$} & \multicolumn{2}{|c|}{$\geq 10^{7}$} & \\
\hline & & $f$ & $p_{i}$ & $f$ & $\mathbf{p}_{\mathrm{i}}$ & $f$ & $\mathbf{p}_{\mathrm{i}}$ & $f$ & $\mathbf{p}_{\mathrm{i}}$ & $f$ & $\mathbf{p}_{\mathrm{i}}$ & $f$ & $p_{i}$ & $f$ & $\mathbf{p}_{\mathrm{i}}$ & $f$ & $\mathbf{p}_{\mathrm{i}}$ & \\
\hline TAMB & 30 & 0 & 0 & 0 & 0 & 0 & 0 & 0 & 0 & 18 & 60 & 3 & 10 & 3 & 10 & 6 & 20 & $5.38 \pm 0.239$ \\
\hline Enterobacteriaceae spp. & 30 & 12 & 40 & 0 & 0 & 0 & 0 & 0 & 0 & 3 & 10 & 12 & 40 & 0 & 0 & 3 & 10 & $3.293 \pm 0.513$ \\
\hline Escherichia coli & 30 & $27 \subseteq$ & 90 & 3 & 10 & 0 & 0 & 0 & 0 & 0 & 0 & 0 & 0 & 0 & 0 & 0 & 0 & $0.13 \pm 0.072$ \\
\hline Koagulaz pozitif Staphylococcus & 30 & 93 & 30 & 6 & 20 & 12 & 40 & 3 & 10 & 0 & 0 & 0 & 0 & 0 & 0 & 0 & 0 & $1.546 \pm 0.22$ \\
\hline Salmonella spp. & 30 & 0 & 0 & 0 & 0 & 0 & 0 & 0 & 0 & 0 & 0 & 0 & 0 & 0 & 0 & 0 & 0 & $0.0 \pm 0.0$ \\
\hline
\end{tabular}


Tablo 3. Mikrobiyolojik sayım sonuçlarına $\left(\log _{10}\right)$ göre garnitür örneklerinin tanımlayıcı istatistiksel sonuçları.

\begin{tabular}{|c|c|c|c|c|c|c|c|c|}
\hline Ölçütü & $\mathbf{S}$ & $\overline{\mathbf{x}}$ & $\mathbf{S}$ & S2 & $S \bar{x}$ & dk. & Max & Ranj \\
\hline TAMB & 161.4 & 5.38 & 1.29 & 1.725 & 0.239 & 4.17 & 7.74 & 3.57 \\
\hline Enterobacteriaceae spp. & 98.81 & 3.293 & 2.81 & 7.896 & 0.513 & 0 & 7.07 & 7.07 \\
\hline Escherichia coli & 3.9 & 0.13 & 0.396 & 0.157 & 0.072 & 0 & 1.3 & 1.3 \\
\hline Koagulaz pozitif Staphylococcus & 44.85 & 1.546 & 1.188 & 1.412 & 0.22 & 0.3 & 3.34 & 3.34 \\
\hline Salmonella spp. & 0 & 0 & 0 & 0 & 0 & 0 & 0 & 0 \\
\hline
\end{tabular}

Tablo 4. Hazırlanan salata sebzeleri ve sosları için mikrobiyolojik kriterler ${ }^{(12)}$.

\begin{tabular}{lcccc}
\hline Ölçütü & Tatmin edici & Kabul edilebilir & Yetersiz & Kabul edilemez/Potansiyel olarak tehlikeli \\
\hline Toplam Aerobik koloni sayısı & $<10^{6}$ & $10^{6}-<10^{7}$ & $\geq 10^{7}$ & $\mathrm{Na}$ \\
Enterobacteriaceae spp. ${ }^{*}$ & $<100$ & $100-<10^{4}$ & $\geq 10^{4}$ & $\mathrm{Na}$ \\
Escherichia coli & $<20$ & $20-<100$ & $\geq 100$ & $\mathrm{Na}$ \\
Staphylocccus aureus & $<20$ & $20-<100$ & $100-<10^{4}$ & $>104$ \\
Salmonella spp. & 25 g'de algılanmadı & & & 25 g'de saptanması \\
\hline
\end{tabular}

Na: Uygulanamaz; *: Taze meyve, sebze ve salata sebzeleri için geçerli değildir.

Tablo 5. Sirkelerin pH'sı ve asitliği.

\begin{tabular}{lcc}
\hline Sirke No & pH & Asitlik (\%) \\
\hline 1 (Ticari) & 2.66 & 4.46 \\
2 (Ticari) & 2.83 & 4.48 \\
3 (Ticari) & 2.86 & 4.12 \\
4 (Geleneksel) & 2.04 & 5.95 \\
\hline
\end{tabular}

Denemede Kullanılan Sirkelerin $\mathrm{pH}$ ve Asitlik Dereceleri: MIK tayini amacıyla kullanılan sirke örneklerinin pH ve asitlik değerleri ölçülmüştür. pH 2.66-3.04 ve asitlik 4.12-5.95 arasında bulunmuştur. ilgili sonuçlar Tablo 5'te gösterilmiştir. Buna göre, incelenen sirkelerin asitliğinin standarda uygun olduğu belirlenmiştir ${ }^{(13)}$.

Minimum Inhibitör Konsantrasyon (MIK) ve İstatistiksel Değerlendirme Sonucları: Sirke örnekle-
Tablo 7. MIK sonuçlarına göre frekans dağılımları, Frekans (f) ve Bağıl frekans (Pi) (\%).

\begin{tabular}{lccc}
\hline Sirke MIK Değeri (\%) & $\mathbf{f}$ & $\mathbf{P i}(\%)$ & Kümülatif \% \\
\hline 0.78 & 3 & 5.4 & 5.4 \\
1.50 & 8 & 14.3 & 19.6 \\
3.12 & 33 & 58.9 & 78.6 \\
6.25 & 12 & 21.4 & 100.0 \\
Toplam & 56 & 100.0 & \\
\hline
\end{tabular}

rine göre betimleyici istatistikler Tablo 6'da, sirkelerin MIK sonuçlarına göre frekans dağılımları Tablo 7'de; sirkelerin tüm MIK verilerine göre betimleyici istatistik sonuçları Tablo 8'de, incelenen bakteri suşlarının MIK değerlerine göre tanımlayıcı istatistikleri Tablo 9'da, gösterilmiştir. Kruskal Wallis testi sonuçlarına göre sirke örneklerinin MIK değerlerinin önemli bir fark gösterdiği saptanmıştır $(p<0.005)$.

Tablo 6. Sirke örneklerine göre betimleyici istatistikler.

\begin{tabular}{|c|c|c|c|c|c|c|c|c|}
\hline \multirow[b]{2}{*}{ Sirke No } & \multirow[b]{2}{*}{$\mathbf{N}$} & \multirow[b]{2}{*}{$\overline{\mathbf{x}}$} & \multirow[b]{2}{*}{$\mathbf{S}$} & \multirow[b]{2}{*}{$S \bar{x}$} & \multicolumn{2}{|c|}{ Ortalama için \%95 Güven Aralığı } & \multirow[b]{2}{*}{ Minimum } & \multirow[b]{2}{*}{ Maksimum } \\
\hline & & & & & Alt sınır & Üst sınır & & \\
\hline 1 & 14 & 3.4436 & 1.65943 & .44350 & 2.4854 & 4.4017 & 1.50 & 6.25 \\
\hline 2 & 14 & 3.8986 & 1.60110 & .42791 & 2.9741 & 4.8230 & 1.50 & 6.25 \\
\hline 3 & 14 & 4.1221 & 1.69952 & .45422 & 3.1409 & 5.1034 & 1.50 & 6.25 \\
\hline 4 & 14 & 2.2714 & 1.04583 & .27951 & 1.6676 & 2.8753 & 0.78 & 3.12 \\
\hline Toplam & 56 & 3.4339 & 1.64850 & .22029 & 2.9925 & 3.8754 & 0.78 & 6.25 \\
\hline
\end{tabular}

Na: Uygulanamaz; *: Taze meyve, sebze ve salata sebzeleri için geçerli değildir. 
Tablo 8. Sirkelerin tüm MIK verilerine göre betimleyici istatistik sonuçları.

\begin{tabular}{|c|c|c|c|c|c|c|c|}
\hline \multirow[b]{2}{*}{$\mathbf{N}$} & \multirow[b]{2}{*}{ Aralığı } & \multirow[b]{2}{*}{ Minimum } & \multirow[b]{2}{*}{ Maksimum } & \multicolumn{2}{|c|}{ Ortalama } & \multirow[b]{2}{*}{$S$} & \multirow[b]{2}{*}{ S2 } \\
\hline & & & & $\overline{\mathbf{x}}$ & $S \bar{x}$ & & \\
\hline 56 & 5.47 & 0.78 & 6.25 & 3.4339 & .22029 & 1.64850 & 2.718 \\
\hline
\end{tabular}

$N=$ Örnek sayısı

Tablo 9. İncelenen bakteri suşlarının MIK değerlerine göre tanımlayıcı istatistikleri.

\begin{tabular}{|c|c|c|c|c|c|}
\hline Suş & $\mathbf{N}$ & Ortalama & Std. Sapma & Minimum & Maksimum \\
\hline Enterobacter cloacae & 3 & 2.7150 & .81000 & 1.50 & 3.12 \\
\hline Enterobacter aerogenes & 3 & 2.7150 & .81000 & 1.50 & 3.12 \\
\hline Enterobacter spp. & 3 & 2.7150 & .81000 & 1.50 & 3.12 \\
\hline Escherichia coli & 3 & 2.3100 & .93531 & 1.50 & 3.12 \\
\hline Escherichia coli & 3 & 2.5350 & 1.17000 & .78 & 3.12 \\
\hline Escherichia hermannii & 3 & 1.3200 & .36000 & .78 & 1.50 \\
\hline Klebsiella pneumoniae & 3 & 3.3175 & 2.24473 & .78 & 6.25 \\
\hline Staphylococcus aureus & 3 & 5.4675 & 1.56500 & 3.12 & 6.25 \\
\hline Staphylococcus aureus & 3 & 3.9025 & 1.56500 & 3.12 & 6.25 \\
\hline Staphylococcus aureus & 3 & 5.4675 & 1.56500 & 3.12 & 6.25 \\
\hline Staphylococcus aureus & 3 & 5.4675 & 1.56500 & 3.12 & 6.25 \\
\hline Staphylococcus aureus & 3 & 3.9025 & 1.56500 & 3.12 & 6.25 \\
\hline Staphylococcus aureus & 3 & 3.1200 & .00000 & 3.12 & 3.12 \\
\hline Staphylococcus aureus & 3 & 3.1200 & .00000 & 3.12 & 3.12 \\
\hline
\end{tabular}

$N=M I K$ belirlenen sirke sayısı

\section{TARTIŞMA}

Bu araştırmada izole edilen Gram negatif bakterilerden yapılan identifikasyon çalışmalarında K. pneumoniae, K. ozaenae, K. oxytoca, E. coli, E. aerogenes, E. hermanii, E. cloacae, H. alvei, A. hydrophila, C. freundii, B. pseudomallei, S. odorifera biogp 1, Salmonella spp. identifiye edilmiştir. Koagülaz pozitif stafilokoklardan da yedi farklı S. aureus belirlenmiştir. Bu sonuçlar yemeye hazır sebzelerin halk sağlığı açısından endişe duyulacak farklı bakteri türleri ile kontamine olabileceğini göstermiştir. Ajayi ve ark. ${ }^{(14)}$, araştırmasında musluk suyu ile yıkanmamış sebzelerde $S$. aureus, Pseudomonas, Bacillus spp., Proteus spp., Streptococcus, E. aerogenes, Micrococcus spp., Lactobacillus ve $E$. coli, sirke ile yıkamış olanlarda ise E. aerogenes, Proteus ve S. aureus saptayabilmiştir. S. aureus tüm sebze örneklerinde belirlenmiştir. Halkman ve Halkman ${ }^{(15)}$, yaptıkları araştırmada, salata, şarküteri ürünleri ve taze meyve ve sebzelerden oluşan 500 adet örnekte E. aerogenes'i, E. coli olmayan fekal koliformlar arasında en yaygın tür olarak belirlemişlerdir. Bu araştırmaların sonuçları mevcut bulgularla yapılan araştır- ma sonuçları benzerdir.

Garnitürlerde ortalama olarak; toplam aerobik mezofilik bakteri (TAMB) $1.5 \times 10^{4}-5.6 \times 10^{7} \mathrm{cfu} / \mathrm{g}$ (4.17-7.24 $\log _{10}$ ) aralığında bulunmuştur. Türk Gıda Kodeksi Mikrobiyolojik Kriterler Tebliği'nde ${ }^{(16)}$ bu ürünler için belirlenmiş bir TAMB spesifikasyonu yoktur. İncelenen örnekler, PHLS (Public Health Laboratory Service) standartlarına göre (Tablo 4), 30 örneğin altı adedinde (\%20) TAMB sayısı "tatmin edici değil" şeklinde bulunmuştur. Türkiye'de dönerle servis edilen garnitürlerin TAMB sayısı ile ilgili yapılmış bir araştırma yoktur. Salatalar için yapılan araştırmalarda ise, genellikle hijyenik kalitelerinin yeterli olmadığı, hatta zaman zaman patojenlerle kontamine oldukları, pişirilmiş gıdalardan daha riskli olduğu saptanmıştır. Bu çalışmanın bulguları yemeye hazır sebzelerin 3-9 $\log _{10}$ cfu/g arasında değişen aerobik mikrobiyal sayılarını bulan çeşitli çalışmalarla uyumludur.

Hampikyan ve ark. ${ }^{(17)}$, İstanbul'da, salatalarda TAMB sayısı $3.8 \times 10^{3}-4.8 \times 10^{6} \mathrm{cfu} / \mathrm{g}$; Ongan ${ }^{(18),}$ huzurevlerinde çalışmasında salata örneklerinde ortalama $8.4 \times 10^{5}$ cfu/g TMAB bildirmiştir. Younus ve ark. ${ }^{(19)}$ tarafından 
üniversite kampüsündeki restoranlardan 60 adet hazır karışık sebze salatası örneği toplanmış, aerobik plaka sayısı $7.73 \pm 0.61$ ile $9.04 \pm 0.26 \log _{10} \mathrm{cfu} / \mathrm{g}$ olarak belirlenmiştir. Ajayi ve ark.'nın ${ }^{(14)}$ çalışmasında, yıkanmamış sebzelerde toplam canlı bakteri $3.8 \times 10^{5}$ $1.2 \times 10^{7} \mathrm{cfu} / \mathrm{g}$, yıkanmış sebzelerde $5.0 \pm 0.7 \times 10^{4}$ seviyesinde bulunmuştur. İncelenen garnitürlerin \%20'sinin TAMB sayısının "tatmin edici değil" olarak belirlenmesi, ürünün tarladan çatala bulaşma olasıllığını ve mikroorganizma üremesi için uygun koşulların varlığına işaret etmektedir. Bununla birlikte, tek başına yüksek TAMB sayıları (> $6 \log _{10} \mathrm{cfu} / \mathrm{g}$ ), zararsız mikroorganizmalardan da kaynaklanabileceğinden, yiyeceklerin düşük mikrobiyolojik güvenliğini kesin olarak göstermez ${ }^{(20)}$.

$\mathrm{Bu}$ çalışmada incelenen garnitürlerde Enterobacteriaceae spp. sayısı $<10-1.2 \times 10^{7} \mathrm{cfu} / \mathrm{g}$ (<1-7.07 $\log _{10}$ ) olarak belirlenmiştir. E. coli sayısı ise $<10-2 \times 10^{1} \mathrm{cfu} / \mathrm{g}\left(<1-1.30 \log _{10}\right)$ miktarında bulunmuştur. Enterobacteriaceae spp., otuz örneğin $18^{\prime}$ inde (\%60), E. coli ise 3 adedinde (\%10) belirlenmiştir. PHLS standardına göre (Tablo 4), incelenen örneklerin 18 tanesi Enterobacteriaceae spp. sayısı $\geq 10^{4}$ şeklinde belirlenmiş olup tatmin edici değil kategorisindedir. E. coli açısından, incelenen 30 örnekten 27'si $<20$ tatmin edici, üç tanesi $20-<100$ aralığında yani kabul edilebilir olarak belirlenmiştir. Koliform grubu bakterilerin varlığı gıdanın genel kalitesi hakkında bilgi verirken, E. coli ve fekal koliformlar gıdanın fekal kontaminasyon seviyesine işaret ederler. Enterobacteriaceae sayımı, geleneksel olarak işlemden sonra hijyen ve kontaminasyon göstergesi olarak kullanılan koliform testlerinin yerini almıştır ${ }^{(20)}$.

Özkan ${ }^{(21)}$, Tekirdağ ve Kırklareli illerinde 95 adet salatanın 40 adedinde koliform bakteri, 46 adedinde ise E. coli saptamıştır. Analiz edilen 95 salatada E. coli; 49 (\%51.4) örnekte belirlenememiş, yedi (\%7.4) örnekte $10^{0}-10^{1}$ adet/g aralığında, 18 (\%18.9) örnekte $10^{1}-10^{2}$ adet/g aralığında, 12 (\%12.6) örnekte $10^{2}-10^{3}$ adet/g aralığında, dokuz (\%9.4) örnekte $>10^{3}$ adet/g saptanmıştır. Koliform 26 (\%27.3) örnekte belirlenememiş 10 (\%10.5) örnekte $10^{0}-10^{1}$ adet/g aralı̆ı̆ında, 19 (\%20.0) örnekte $10^{1}-10^{2}$ adet/g aralığında, 16 (\%16.8) örnekte $10^{2}-10^{3}$ adet/g aralığında, 24 (\%25.2) örnekte $>10^{3}$ adet/g saptanmıştır. Ongan ${ }^{(18)}$, huzurevlerinde 25 salata örneğinin \%88.0'inde koliform (ortalama $1.7 \times 10^{4} \mathrm{cfu} / \mathrm{g}$ ) ve $\% 12.0^{\prime}$ sinde E. coli (>100 cfu/g) saptamıştır. Koliform grubu mikroorganizmaların $1.5 \times 10^{2}$ ile $1.4 \times 10^{5} \mathrm{cfu} / \mathrm{g}$ değerleri arasında değişen düzeylerde bulunduğu belirlenmiştir. Meldrum ve ark. ${ }^{(4)}$ tarafından, İngiltere'de kebap paket servis restoranlarında, döner salata sebze ve soslarının mikrobiyolojik güvenliğini belirlemek amaçlı olarak yapılan bir araştırmada, 1.213 sebze salatası örneğinin \% 4.7'sinin E. coli ile kontamine olduğu belirlenmiştir. Bangladeş'te farklı restoranlardan 60 adet yemeye hazır karışık sebze salatası örneği toplanmış, E. coli $4.98 \pm 0.20$ ila $6.66 \pm 0.80$ log cfu/g miktarında bulunmuştur ${ }^{(19)}$. Ajayi ve ark.'nın ${ }^{(14)}$ araştırmasında, Enterobacteriaceae spp. yıkanmamış sebzelerde $1.2 \times 10^{6}-2.1 \times 10^{7} \mathrm{cfu} / \mathrm{g}$; yıkanmışlarda $2.8 \pm 0.7 \times 10^{5}$ $1.9 \pm 0.0 \times 10^{7} \mathrm{cfu} / \mathrm{g}$ miktarında saptanmıştır.

Incelenen örneklerin 18 tanesi Enterobacteriaceae spp. sayısı $\geq 10^{4}$ şeklinde belirlenmiş olup, tatmin edici değil kategorisindedir. Ancak Enterobacteriaceae için listelenen PHLS tarafından önerilen bu kriterler, taze meyve ve sebzeler veya salata sebzeleri içeren sandviçler için geçerli değildir; çünkü taze meyve ve sebzeler genellikle normal florasının bir parçası olarak bu organizmaları yüksek seviyelerde taşırlar ${ }^{(12)}$.

Salmonella Enterobacteriaceae ailesinde bulunan, Gram negatif, fakültatif anaerobik, kapsülsüz, sporsuz bir basil olup, doğada yaygındır ve hem evcil hem de vahşi tüm hayvan türlerinin bağırsak yolunda bulunabilir ve dünya çapında gıda kaynaklı hastalıkların önde gelen nedenlerinden biridir. Geçmişte birçok çalışmada, Salmonella türleri taze sebzelerden izole edilmiştir ve sebzelerle ilişkili bir dizi salmonelloz salgını bildirilmiştir ${ }^{(22)}$. Bitkisel ürünlere genellikle çapraz kontaminasyon yoluyla, kanalizasyon suları ile sulama veya gıdaları yıkama ile salmonella bulaşı olmaktadır. Türkiye'de döner vb. gıdaların yanında verilen garnitür yeşil salata bu açıdan risk taşımaktadır.

Taze kesilmiş meyve ve sebzelerde, Salmonella spp için mikrobiyolojik kriter 25 g gıdada sıfırdır ${ }^{(12)}$. Çiğ yenen yapraklı sebzeler, üretime bağı salmonelloz 
salgınlarının en yaygın nedeni olarak tanımlanmıştır(23). Bu çalışmada, ISO 6579-1 yöntemi kullanılarak yapılan garnitürlerin bir adedinde Salmonella spp. saptanmamıştır. Bununla birlikte, Violet Red Bile Glucose Agar ortamından tanımlama için rastgele seçilen bir koloni Salmonella spp. olarak tanımlanmıştır.

Hampikyan ve ark. ${ }^{(17)}$ tarafından İstanbul'da tüketilmek üzere salatalar üzerinde yapılan bir araştırmada, Salmonella'ya herhangi bir örnekte rastlanmamıştır. Özkan (21) 95 salatada Salmonella spp. belirleyememiştir. Ongan'ın ${ }^{(18)}$ huzurevlerinde yaşlılara sunulan salata örneklerini incelediği çalışmada, Salmonella spp. izole edilememiştir. Gökmen ve ark. ${ }^{(24)}$ tarafından bazı hazır gıdalarda (20 Rus salatası, 40 sebze salatası) yapılan mikrobiyolojik analiz sonucunda, salata örneklerinde Salmonella spp. saptanmamıştır. Bununla birlikte, Bangladeş Üniversitesi Kampüsü'ndeki farklı restoranlardan yemeye hazır çiğ sebze ve karışık sebze salatası örneklerinde ${ }^{(19)}$ ve Çin'deki çoğu eyalet başkentini kapsayan bir çalışmada, çiğ sebze örneklerinde Salmonella belirlenmesi ${ }^{(25)}$ gibi çalışmalar, birçok ülkede tüketime hazır çiğ sebzelerde Salmonella salgını riskinin devam ettiğini göstermektedir.

Bu araştırmada, S. aureus $<10-3.4 \times 10^{2} \mathrm{cfu} / \mathrm{g}(<1-2.53$ $\log _{10}$ ) miktarında belirlenmiştir. Koagulaz pozitif Staphylococcus sayısının örneklerin \%50'sinde $\geq 10^{2}$ cfu/g düzeyinde belirlenmesi yetersiz mikrobiyolojik kaliteyi göstermektedir. Meldrum ve ark. ${ }^{(4)}$ tarafından İngiltere'de, kebap paket servis restoranlarında servis edilen salata sebzelerinde \%3.7 S. aureus $\left(\geq 10^{2}-<10^{4} \mathrm{cfu} / \mathrm{g}\right)$ belirlenmesi nedeniyle yetersiz mikrobiyolojik kaliteye sahip olduğu saptanmıştır. Ajayi ve ark.'nın ${ }^{(14)}$ araştırmasında, stafilokoklar yıkanmamış sebzelerde $1.3 \times 10^{7}-2.6 \times 10^{7} \mathrm{cfu} / \mathrm{g}$, yıkanmış olanlarda $3.8 \pm 0.7 \times 10^{5}-9.8 \pm 0.7 \times 10^{6} \mathrm{cfu} / \mathrm{g}$ olarak belirlenmiştir. Hampikyan ve ark. ${ }^{(17)}$, İstanbul'da tüketime sunulan salatalarda, \%20 koagülaz (+) S. aureus (10²$\left.10^{4} \mathrm{cfu} / \mathrm{g}\right)$ belirlemişlerdir. Özkan'ın ${ }^{(21)}$ araştırmasında, Tekirdağ ve Kırklareli illerinde çeşitli yemek üretim tesisleri ve lokantalarda tüketime sunulan 95 adet salata örneğinin \%3.9'unun $>10^{2}$ cfu/g seviyelerinde koagülaz pozitif $S$. aureus taşımaları nedeniyle ilgili yönetmeliğe uymadıkları saptanmış ve halk sağlığı açısından riskli olarak değerlendirilmiştir. Bangladeş'te farklı restoranlardan toplanan 60 adet yemeye hazır karışık sebze salatası örneğinde, Staphylococcus spp. 4.64 $\pm 0.61-6.42 \pm 0.53 \log _{10}$ cfu/g olarak belirlenmiştir ${ }^{(19)}$. Ongan ${ }^{(18)}$ huzurevlerinde yaşIılara sunulan beslenme hizmetlerinin değerlendirilmesi amacıyla yaptığı araştırmada, incelenen salata örneklerinin \%44.0'ünde $S$. aureus saptanmış, ortalama $7.7 \times 10^{2} \mathrm{cfu} / \mathrm{g}$ düzeyinde belirlenmiştir. $S$. aureus, Gram pozitif, kok seklinde, sporsuz, hareketsiz aerobik Micrococaceae familyası genel özelliklerini taşıyan mezofilik bir organizmadır. Bu mikroorganizma, insanların deri ve mukozal (boğaz ve burun) florasında yaygın olarak bulunduğundan en önemli kaynağı insandır ve personel hijyeni çok önemlidir. Özellikle üretim esnasında, çok fazla el teması olan ve hazırlanarak oda sıcaklığında uzun süre bekletilen gıdalar risklidir. Intoksikasyon tipte gıda zehirlenmesine yol açan enterotoksin oluşturur. Türk Gıda Kodeksi Yönetmeliği'ne $(2002)^{(16)}$ göre hazır yiyeceklerde bu etken sayısının $1.0 \times 10^{2} \mathrm{cfu} / \mathrm{g}(\mathrm{mL})$ değerini aşmaması gerektiği bildirilmiştir. $\mathrm{Bu}$ çalışmada, örneklerin bazılarının $>10^{2} \mathrm{cfu} / \mathrm{g}$ seviyelerinde koagülaz pozitif $S$. aureus taşımaları nedeniyle ilgili yönetmeliğe uymadıkları saptanmış ve halk sağlığı açısından riskli olarak değerlendirilmiştir.

Döner kebap eşliğinde servis edilen garnitürlerle ilgili olarak yapılan bu araştırma sonuçları genel olarak değerlendirildiğinde, incelenen örneklerin $\% 20$ 'sinde toplam aerobik koloni sayısının (TAMB) $\geq 10^{7}$, \%60'ında Enterobacteriaceae spp. sayısının $\geq 10^{4}$, koagulaz pozitif Staphylococcus sayısının örneklerin $\% 50$ 'sinde $\geq 10^{2} \mathrm{cfu} / \mathrm{g}$ düzeyinde belirlenmesi ve bir örnekte de Salmonella spp. saptanmış olması yetersiz mikrobiyolojik kaliteyi ortaya koymuştur. Kebaplarla servis edilen açık yiyecekler tarladan çatala tüm aşamalarda kontamine olabilir. Özellikle $E$. coli ve koagülaz pozitif $S$. aureus içeren örneklerin halk sağlığı için potansiyel risk taşıdığı söylenebilir. Yemeye hazır sebzelerin bakteriyel kontaminasyona maruz kalma sebebi sebzelerin etkin yıkanmaması, yıkama suyunun içme suyu niteliklerinin taşımaması, çapraz bulaşma veya ürünün hazırlanması sonrası olan kontaminasyonlardır. 
Göktaş'ın ${ }^{(26)}$ İstanbul'da kebap servisi yapan restoranları da içeren araştırmasında, 50 gıda işletmesinde 2.350 adet kritik nokta görsel olarak incelenmiş ve bunlardan \%34.3'ünün (805 adet) hijyen açısından uygun olmadığı saptanmıştır. Yapılan mikrobiyolojik çalışmalar sonucunda ise, incelenen 100 personel eli örneğinin \%39'unun, 100 adet alet ekipman yüzey örneğinin \%42'sinin (42 adet) uygun olmadığı belirlenmiştir. Gıda güvenliği sisteminde $\% 52.7$, aletmalzeme hijyeninde $\% 46.3$ ve personel hijyeninde \%36.3 oranında uygunsuzluk saptanmıştır. Isı işlem görmeden hazırlanan ve tüketime sunulan garnitürlerin mikrobiyolojik analiz sonuçlarının istanbul'da restoranların hijyen açısından uygunluğunu da yansıttığı düşünüldüğünde, bu araştırmanın sonuçları Göktaş'ın ${ }^{(26)}$ araştırması ile de uyumludur ve bu işletmelerde gıda güvenliği yönetimine yönelik uygulamalara daha sıkı uyulması gerekliliğine işaret etmektedir.

Yemeye hazır, tüketime sunulan taze sebzelerin yıkanmasında insan sağlığına zararı olmayan dezenfektan maddelerin kullanımının önemi bu sonuçlardan da anlaşılmaktadır. Klor bazlı ürünler, kullanımla ilgili bazı güvenlik endişelerine rağmen (Örneğin, trihalomethane oluşumu), gıda işletmelerinde ve evlerde kullanılmak üzere uygun ve ucuz bir dezenfektan olarak kabul edilmiştir. Temiz ve ark. ${ }^{(27)}$ çalışmalarında, Ankara'daki marketlerden temin ettikleri yapraklı sebzelerin tek başına musluk suyuna batırılma süreci mikrobiyal popülasyonun azaltılmasında etkili bulunmamıştır. Klor (200 mg/l) ve asetik asit $(\% 0.25, \mathrm{v} / \mathrm{v})$ ile yıkandıktan sonra toplam mezofilik bakterilerin azalması ve toplam koliform sayılarında istatistiksel olarak anlamlı bir fark belirlenmemiştir. Nascimento ve ark. ${ }^{(28)}$, su ve sekiz dezenfektan çözeltisi (\%6.25 ve $\% 50$ sirke; $\% 2$ ve $\% 4$ asetik asit; 80 ppm perasetik asit, 200 ppm sodyum hipoklorit ve 200 ppm sodyum dikosocyanurate) marul etkinliğinin doğal mikrobiyotasına karşı karşılaştırıımıştır. Sonuçların istatistiksel analizi, test edilen tüm dezenfektan ajanlarının etkinlik seviyelerinin 200 ppm sodyum hipoklorit seviyesine eşit veya daha yüksek olduğunu göstermiştir. Bu sonuçlara göre, asetik asidin gıda işletmelerinde ve yapraklı sebzelerin ev seviyesinde yüzey dekontaminasyon uygulamalarında klora alternatif olabileceği görülmektedir.
Bu araştırmada, piyasadan alınan üç farklı marka ticari üzüm sirkesi ve bir de üreticiden alınan geleneksel doğal sirkenin garnitürlerden izole edilen bazı Gram negatif bakteriler ve yedi farklı $S$. aureus suşu üzerine antimikrobiyal etkisi incelenmiş ve kullanılan sirkeye ve incelenen bakteriye bağlı olarak \%1.5-6.25 arasında değişen oranda sirkenin mikroorganizmalar üzerine etkin olduğu saptanmıştır. Genel olarak S. aureus suşları için Gram negatiflerden daha yüksek oranda sirkeye $(\% 6.25)$ gereksinim duyulduğu belirlenmiştir. Erzurum'da Elhan ${ }^{(29)}$ tarafından sirkenin salata dezenfeksiyonu için etkinliğini belirlemek amacıyla yapılan çalışmada, salata dezenfeksiyonunda sirke \%3 konsantrasyonunun kullanılabileceği saptanmıştır. Jayamma ve ark. ${ }^{\left({ }^{(30)}\right.}$ araştırmasında, sebzelerin yüzey kirlenmesinin yüzey mikroflorasını azaltmak için en etkili yöntemin 10 dakika boyunca \%3 sirke ile muamele olduğu belirlenmiştir. Srinivasan ve ark.'nın ${ }^{(31)}$ araştırmasında, sirkenin \%2.5 ile en etkili olduğu bulunmuştur. Bahsedilen çalışmaların sonuçları bu araştırmanın sonuçları ile uyumludur. Aliasghari ve ark. ${ }^{(32)}$ tarafından farklı konsantrasyonlarda olan geleneksel üzüm sirkelerinin Streptococcus mutans, Streptococcus sobrinus, Streptococcus sanguis ve Streptococcus salivarius üzerinde antimikrobiyel etkileri incelenmiştir. En yüksek inhibisyon zonu 1 $\mathrm{mg} / \mathrm{ml}$ konsantrasyonda hazırlanan sirke ile S. salivarius üzerinde belirlenmiştir.

Karapinar ve Gönül ${ }^{(33)}$ tarafından yapılan bir çalışmada, \%1, 2 ve 5 asetik asit içeren, ayrıca, \%30, 40 ve 50 sirke içeren çözeltiler ile çiğ maydonozda dekontaminasyon çalışmaları yapılıış, çalışma sonuçlarına göre \%2ve 5'likasetikasitçözeltileri Yersiniaenterocolitica'yı inhibe etmiştir. Wu ve ark. ${ }^{(34)}$ tarafından yapılan bir çalışmada, \%5.2 ve daha yüksek asetik asit konsantrasyonuna sahip sirke ile muamele etmenin maydanoz yapraklarındaki Shigella sonnei üzerinde inhibe edici etkisinin olduğu belirtilmiştir. Choi ve ark.'nın ${ }^{(35)}$ geleneksel kahverengi pirinç sirkelerinin antimikrobiyal etkinliğinin belirlendi çalışmada S. aureus, E. coli, Listeria monocytogenes, Pseudomonas aeruginosa, S. Typhimurium, $Y$. enterocolitica üzerinde yüksek düzeyde antimikrobiyal etki belirlenmiştir. 
Üzüm sirkesi dışında farklı sirkelerle yapılan dekontaminasyon çalışmaları da vardır. Ev yapımı ve ticari dut sirkesinin mikrobiyolojik özelliklerini inceleyen Şengün ve Kılıç'ın ${ }^{(36)}$ çalışmasında, ev yapımı geleneksel sirke E. coli $\mathrm{O} 157 \mathrm{H7}$, S. Typhimurium, Bacillus subtilis, Enterococcus faecalis, Pediococcus acidilactici üzerinde etkili olmuştur.

Geleneksel yöntemle üretilen ve üretim sırasında içeriğine bal katılan yaban mersini sirkesi ve bal sirkesinin antimikrobiyal etkisi, E. coli ATCC 25922, S. Typhimurium ATCC 0028, B. subtilis ATCC 19659, S. aureus ATCC 25923, Candida albicans ATCC 118804 ve Candida tropicalis ATCC 13803 suşları ile araştırılmıştır ${ }^{(37)}$. Sonuç olarak, geleneksel yaban mersini sirkesinin S. Typhimurium ATCC 0028 ve B. subtilis ATCC 19659 üzerinde antimikrobiyal etkisi olduğu belirlenmiştir. Yang ve ark. ${ }^{(38)}$, Litchi chinensis kullanılarak elde edilen odun sirkesinin E. coli 25257, Acinetobacter baumannii 814, S. aureus 985, $P$. aeruginosa 717 ve ornithine dirençli $S$. aureus ile araştırılmış ve ağaç sirkesinin S. aureus 985 ve P. aeruginosa $717(0.95-1.90 \mu \mathrm{l} / 100 \mu \mathrm{l})$ üzerinde önemli antimikrobiyal etkisi belirlenmiştir. Bakır ve ark. ${ }^{(39)}, S$. Typhimurium, E. coli ve $S$. aureus üzerinde 18 farklı sirke örneğinin (Elma, üzüm, nar, balzamik, yaban mersini, kuşburnu, kobay, limon, böğürtlen, enginar, kayısı, alıç, narenciye, dut, pirinç sirkesi) antimikrobiyal faaliyetleri incelemiştir ve balzamik sirkenin en yüksek antimikrobiyal aktiviteye sahip olduğu, genel olarak incelenen sirkelerin çoğunun söz edilen mikroorganizmalara karşı orta derecede antimikrobiyal aktivitesi bulunduğu belirlenmiştir. Yagnik ve ark. ${ }^{(40)}$ tarafından yapılan çalışmada, ticari elma sirkesinin inhibisyon etkisi gösterebilmesi için gerekli olan minimum inhibisyon konsantrasyonları, C. albicans için $250 \mu \mathrm{g} / \mathrm{ml}$, E. coli için $62 \mu \mathrm{g} / \mathrm{ml}$ ve S. aureus için $125 \mu \mathrm{g} / \mathrm{ml}$ olarak belirlenmiştir.

Farklı mikroorganizma türleri ve farklı suşlarla yapıIan bazı çalışmaların sonuçları bu araştırma ile tutarlıyken, diğerleri biraz farklılık göstermektedir. Bunun nedeni, sirke türü, kalitesi, mikroorganizma türü ve suşlarındaki farklılıklar dışında doğrudan örnekler üzerinde yapılan çalışmalarda, toplam mikroorganizma yükü ve diğer safsızlıklardır.
Bu çalışmadan elde edilen sonuçlar, İstanbul'da döner kebap restoranlarında tüketicilere servis edilen garnitürlerinin yeterli mikrobiyolojik kalitede olmadığını, zaten önemli bazı riskler içeren döner kebapların yanı sıra servis edilen kontamine taze sebzelerin tüketilmesinin de sağılı sorunlarına yol açabileceğini göstermiştir. Salata olarak çiğ yenen yapraklı sebzeler, taze ürün güvenliği açısından birinci öncelik grubu olarak kabul edilmiştir. Bir ürün ne kadar çok işlenirse, florası üretildiği ortamın florasını o kadar yansıtır. İyi Üretim Uygulamaları (GMP) ve İyi Hijyen Uygulamalarına (GHP) uyulmaması, taze kesim sebzeleri işleme için önemli risk faktörüdür. İyi gıda hijyeni uygulamaları, çapraz kontaminasyon yoluyla yemeye hazır taze gıdalardan gıda kaynaklı hastalık bulaşma riskini büyük ölçüde azalttır. Garnitürlerin gün boyu oda koşullarında saklanması için modifiye atmosfer ambalajı da önerilebilir. Bu yöntem, soğutma ile birlikte mikrobiyal üremeyi yavaşlatır, fizyolojik yaşlanmayı geciktirir ve böylece raf ömrünü uzatır. Sonuç olarak, kebapla servis edilen taze sebzelerin hazırlanması ve servislerinde gıda güvenliği yönetimine yönelik kurallara sıkı bir şekilde uyulmalı ve restoranlarda kamu denetimlerinde çiğ tüketime hazır sebzelerin sağlık riski de göz önünde bulundurulmalıdır.

Çıkar Çatışması: Yazarlar bu makale ile ilgili herhangi bir çıkar çatışması bildirmemişlerdir.

Conflict of Interest: No conflict of interest was declared by the authors.

\section{KAYNAKLAR}

1. Marchetti R, Casadei MA, Guerzoni ME. Microbial population dynamics in ready-to-use vegetable salads. Ital J Food Saf.1992;4(2):97-108.

2. Beuchat LR. Pathogenic microorganisms associated with fresh produce. J Food Prot. 1996;59(2):204-16. https://doi.org/10.4315 / 0362-028X-59.2.204

3. Altunbag $E$, Zencir $E$. Türk ve Akdeniz yemeklerinde sirke kullanımı. J Gastronom Hospitality Travel. 2018;1(2):45-54. https://doi.org/10.33083/joghat.2018.9

4. Meldrum RJ, Little CL, Sagoo S, Mithani V, McLauchlin J, De Pinna E. Assessment of the microbiological safety 
of salad vegetables and sauces from kebab take-away restaurants in the United Kingdom. Food Microbiol. 2009;26(6):573-7.

https://doi.org/10.1016/j.fm.2009.03.013

5. Cunniff P. Official Methods of Analysis. $16^{\text {th }}$ edition. Washington DC: Association of Official Analytical Chemists, 1995:930-35.

6. ISO 4833:2003. Microbiology of food and animal feeding stuffs horizantal method for the enumeration of microorganisms colony count technique at $30^{\circ} \mathrm{C}$. 9s, The International Organization for Standardization, İsviçre, 2003.

7. Harrigan WF, McCance ME. Laboratory methods in food and dairy microbiology. London: Academic Press, 1976.

8. ISO 16649-1:2018. Microbiology of the food chain Horizontal method for the enumeration of betaglucuronidase-positive Escherichia coli - Part 1: Colony-count technique at 44 degrees $\mathrm{C}$ using membranes and 5-bromo-4-chloro-3-indolyl betaDglucuronide. The International Organization for Standardization, İsviçre, 2018.

9. ISO 6888-2:2003. Horizontal method for the enumeration of coagulase-positive staphylococci Part-2: Technique using rabbit plasma fibrinogen agar medium, Microbiology of food and animal feeding stuffs. The International Organization for Standardization, İsviçre, 2003.

10. ISO 6579:2017. Horizontal method for the detection, enumeration and serotyping of Salmonella Part 1: Detection of Salmonella spp. Microbiology of the food chain. The International Organization for Standardization, İsviçre, 2017.

11. Baldas B, Altuner EM. The antimicrobial activity of apple cider vinegar and grape vinegar, which are used as a traditional surface disinfectant for fruits and vegetables. Commun Fac Sci Univ Ank Series C. 2018;27(1):1-10.

https://doi.org/10.1501/commuc_0000000187

12. Gilbert RJ, De Louvois J, Donovan T, et al. Guidelines for the microbiological quality of some ready-to-eat foods sampled at the point of sale. PHLS Advisory Committee for Food and Dairy Products. Commun Dis Public Health.2000;3(3):163-7.

13. TS 1880 EN 13188. Sirke-Tarım kökenli sıvılardan elde edilen ürün-Tarifler, özellikler, işaretleme. Ankara: Türk Standartları Enstitüsü, Türkiye, 2003.

14. Ajayi OA, Amokeodo MI, Akinwunmi OO. Microbial quality of selected ready to eat vegetables from Iwo, Nigeria and effectiveness of rinsing agents. Appl Trop Agric. 2017;22(2):131-7. https://doi.org/10.13140/RG.2.2.35068.90249

15. Halkman HBD, Halkman AK. Gıdalarda Escherichia coli olmayan fekal koliformlar üzerine bir araştırma. Orlab On-Line Mikrobiyoloji Dergisi. 2004;02(02):1-5. http:// www.mikrobiyoloji.org/pdf/702040201.pdf (Erişim Tarihi: 08.03.2021)

16. Resmî Gazete. Türk Gıda Kodeksi Mikrobiyolojik Kriterler Yönetmeliği. (29 Aralık 2011) Resmî Gazete. 2011:28157.

17. Hampikyan $H$, Ulusoy $B$, Bingöl EB, Çolak H, Akhan M. İstanbul'da tüketime sunulan bazı ızgara tipi gıdalar ile salata ve mezelerin mikrobiyolojik kalitelerinin belirlenmesi. Türk Mikrobiyol Cemiy Derg. 2008;38(2):87-94.

18. Ongan D. Huzurevlerinde yaşlılara sunulan beslenme hizmetlerinin değerlendirilmesi ve yaşlıların beslenme durumlarının saptanması. [Doktora tezi] Ankara: Hacettepe Üniversitesi, Sağlık Bilimleri Enstitüsü, Beslenme ve Diyetetik Programı, 2012.

19. Younus MI, Sabuj AAM, Haque ZF, et al. Microbial risk assessment of ready-to-eat mixed vegetable salads from different restaurants of Bangladesh Agricultural University campus. J Adv Vet Anim Res. 2020;7(1):3441. https://doi.org/10.5455/javar.2020.g390

20. Faour-Klingbeil D, Todd EC, Kuri V. Microbiological quality of ready-to-eat fresh vegetables and their link to food safety environment and handling practices in restaurants. LWT. 2016; 74: 224-33. https://doi.org/10.1016/j.Iwt.2016.07.051

21. Ozkan, M. Tüketime sunulan günlük hazır yemekler ve salataların mikrobiyolojik kalitesinin belirlenmesi. [Yüksek lisans tezi] Tekirdağ: Namık Kemal Üniversitesi, Fen Bilimleri Enstitüsü, Gıda Mühendisliği Anabilim Dalı, 2009.

22. Angelo KM, Chu A, Anand M, et al. Outbreak of Salmonella Newport infections linked to cucumbers-United States, 2014. MMWR Morb Mortal Wkly Rep 2015;64(6):144-47.

23. Castro-Ibáñez I, Gil MI, Allende A. Ready-to-eat vegetables: Current problems and potential solutions to reduce microbial risk in the production chain. LWT Food Sci Technol. 2017;85(Part B):284-92. https://doi.org/10.1016/j.Iwt.2016.11.073

24. Gökmen M, Akkaya L, Kara R, Onen A. Balıkesir'de satışa sunulan bazı tüketime hazır gıdalarda Salmonella spp. ve Listeria monocytogenes'in yaygınlığı. Van Vet J. 2016;27(1):31-6.

25. Yang $X, W u$ Q, Huang J, et al. Prevalence and characterization of Salmonella isolated from raw vegetables in China. Food Control. 2020; 109: 106915. https://doi.org/10.1016/j.foodcont.2019.106915

26. Göktaş MA. İstanbul'da bazı gıda işletmelerinde hijyenik kalitenin saptanması. [Yüksek lisans tezi] İstanbul: İstanbul Sabahattin Zaim Üniversitesi, Fen 
Bilimleri Enstitüsü, Gıda Mühendisliği Anabilim Dalı, 2019.

27. Temiz A, Bağcı U, Özmen Toğay S. Efficacy of different decontamination treatments on microbial population of leafy vegetables. Gıda. 2011;36(1):9-15.

28. Nascimento MS, Silva N, Catanozi M, Silva KC. Effects of different disinfection treatments on the natural microbiota of lettuce. J Food Protect. 2003;66(9):1697700 .

https://doi.org/10.4315/0362-028x-66.9.1697

29. Elhan S. Farklı sirke çeşitleri ve konsantrasyonlarının salata bileşenlerinin dezenfeksiyonunda kullanım imkanlarının araştırılması. [Yüksek lisans tezi] Erzurum: Atatürk Üniversitesi, Fen Bilimleri Enstitüsü, Gıda Mühendisliği Ana Bilim Dalı, 2014.

30. Jayamma P, Reddy RR, Kumar RN, Srineetha U. Effect of vinegar on surface microflora of fruits and vegetables. Trend Biosci. 2017;10(33):7172 -6.

31. Srinivasan K, Karuppan P. Effect of antibacterial activity of vinegar on microorganisms analysed from fresh vegetables and fruits. J Biol Chem Res. 2016;33(1):95103.

32. Aliasghari A, Khorasgani MR, Khoroushi M. The effect of vinegar, rose water and ethanolic extract green tea against oral Streptococci, an in vitro study. J Prob Health, 2017;5(4):186.

https://doi.org/10.4172/2329-8901.1000186

33. Karapinar M, Gonul SA. Removal of Yersinia enterocolitica from fresh parsley by washing with acetic acid or vinegar. Int J Food Microbiol. 1992;16(3):261-4. https://doi.org/10.1016/0168-1605(92)90086-I

34. Wu F, Doyle M, Beuchat L, Wells J, Mintz E, Swaminathan B. Fate of Shigella sonnei on parsley and methods of disinfection. J Food Prot. 2000;63(5): 568-72. https://doi.org/10.4315/0362-028x-63.5.568

35. Choi HJ, Gwak KJ, Choi DB, Park JY, Cheong HS. Antimicrobial efficacy of fermented dark vinegar from unpolished rice. Microbiol Biotechnol Lett. 2015;43(2):97-104. https://doi.org/10.4014/mbl.1504.04005

36. Şengün IY, Kılıc G. Dut sirkesinin mikrobiyolojik, fiziksel, kimyasal, antiradikal ve antimikrobiyal özellikleri. Akademik Gıda. 2018;16(2):168-75. https://doi.org/10.24323/akademik-gida.449860

37. Fonseca MS, Santos VAQ, Calegari GC, Dekker RFH, Barbosa-Dekker AM, Cunha MAA. Blueberry and honey vinegar: Successive batch production, antioxidant potential and antimicrobial ability. Braz J Food Technol. 2018;21:e2017101.

https://doi.org/10.1590/1981-6723.10117

38. Yang JF, Yang CH, Liang MT, Gao ZJ, Wu YW, Chuang LY. Chemical composition, antioxidant, and antibacterial activity of wood vinegar from Litchi chinensis. Molecules. 2015;21(9):1150.

https://doi.org/10.3390/molecules21091150

39. Bakır S, Devecioglu D, Kayacan S, Toydemir G, Karbancioglu Guler F, Capanoglu E. Investigating the antioxidant and antimicrobial activities of different vinegars. Eur Food Res Technol. 2017;243(12):208394. https://doi.org/10.1007/s00217-017-2908-0.

40. Yagnik D, Serafin VJ, Shah A. Antimicrobial activity of apple cider vinegar against Escherichia coli, Staphylococcus aureus and Candida albicans; downregulating cytokine and microbial protein expression. Sci Rep. 2018;8(1):1732. https://doi.org/10.1038/s41598-017-18618-x 